\title{
ECONOMIC RATIONALE FOR PROTECTED GEOGRAPHICAL IDENTIFICATION INTRODUCTION FOR LATVIAN CANNED SPRATS
}

Irina PILVERE, Faculty of Economics and Social Development, Latvia University of Agriculture, Svetes street 18, Jelgava, LV3001, Latvia, irina.pilvere@ 1lu.lv (corresponding author)

Mihails SILOVS, Faculty of Economics and Social Development, Latvia University of Agriculture, Svetes street 18, Jelgava, LV3001, Latvia, mihails.silovs@gmail.com

The article raises the question of economic rationale of including Latvian sprat to the protected geographical identification (GI) register of the European Commission. GIs aims to address the situation of asymmetric information on the market specifically a situation when high-quality foodstuffs customers' loyalty and trust can be jeopardized by presence of sub-optimal products. One of the means to help customers and producers confront the information asymmetries and possess more control over the situation is the institute of trademarking. GIs can be understood as a type of trademarking, however, since the GI does not belong to a single company but rather to a product and is used by many companies simultaneously, the GIs are rather seen as a type of collective monopoly right reinforcing collective responsibility of producers. The aim of the current research to evaluate theoretical and economic background of GIlabelling and possibilities for GIs introduction to canned sprat industry in Latvia as well as sketch the relevance of GI introduction to Latvian canned sprats. According to the economic theory, a number of acute problems in the canned sprat industry in Latvia can be resolved by participating in the GI scheme and protecting the traditional producing of Latvian sprat at the European level. Latvian canned sprats is one of the food stuffs that would benefit from the certification both in the local market and exported. The key structural events to be mobilized to realize the potential of a GI-labelling introduction to the canned sprats sector in Latvia are indicated in the article along with the GIs theoretic introduction and discussion.

Keywords: canned sprats, high-quality added value foodstuff, Latvia, Protected Geographical Identifications

\section{INTRODUCTION}

The debate around Protected Geographical Identifications (GI) has been ultimately focused on the question whether the introduction of GI would result in a sufficient gross margin for producers, if any. Whereas at the macro level, GI is associated with country and regional prestige and competitive advantages, indirect investment to other nonproduction industries, i.e. tourism. GIs are largely associated with rural areas and region development. Promoting local production by assigning geographically non-transferrable quality schemes and associated benefits lead to saving work places and potentially employment increase in a specific region. For instance, Moschini et al (2008) indicate clear welfare gains resulting from the GIs introduction in a region. Their findings suggest that GIs are directly related to a competitive provision of quality concerning virtually all the relevant foodstuff producers in a region that partly overcomes the market failure associated with information asymmetry. There are many examples where the general welfare has been preserved and multiplied by introducing protection of traditions and places of production (Champagne, Parma ham, etc.).

Globally, protection of GIs has been implemented for almost as long as intellectual property protection. Following the introduction of the GI protection for wines and spirits (appellation controls), in 1992 the European Union presented the first regulation on the protection of designations of origin for agricultural products and foodstuffs (Regulation 2081/92). In 2012, the Regulation 1151/2012 on quality schemes was adopted to communicate the distinguishing characteristics, production peculiarities and geographical origins. The objectives of the Regulation 1151/2012 are fourfold: ensuring fair competition for farmers and producers of agricultural products and foodstuffs having value-adding characteristics and attributes, providing reliable information about these products to consumers, while indicating a certain level of quality, safeguarding intellectual property rights and the integrity of the internal market (Article 1 of Regulation 1151/2012). Thus, for producers it means also a reputational element providing grounds for legal protection against market opportunists exploiting a well-known foodstuff's name potentially jeopardizing a product reputation and customers' associated trust and loyalty.

The Regulation 1151/2012 introduces three quality schemes aimed to identify and communicate value-adding characteristics of a certain foodstuff with unique farming or processing approach or with traditional features that are

Copyright (C) 2017 The Authors. Published by Aleksandras Stulginskis University. This is an open-access article distributed under the terms of the Creative Commons Attribution License (CC-BY 4.0), which permits unrestricted use, distribution, and reproduction in any medium, provided the original author and source are credited. 
closely linked to a geographical place of their production. The current EU food legislation defines three types of Geographical Indications (see. i.e. Blakeney, 2014; Takenaka, 2013):

- A Protected Designation of Origin (PDO): where a product's quality or characteristics are essential due to a specific geographic area: all stages of processing, including processing of raw materials, as well as final product packaging should be carried out exclusively in this specific geographic area. A producer (or a group of producers) should also prove that elsewhere in the world such a foodstuff is not produced and, if produced, its quality, reputation or other characteristics are strictly different. Most recognizable examples of PDOs are cheeses (such as Queso Manchego or Feta), cured meats (such as Prosciutto di Parma), olive oils, fruits and vegetables and wines.

- A Protected Geographical Indication (PGI): where at least one stage of a foodstuff production, i.e. production, processing or preparation, must take place in a certain geographical area and where a specific quality reputation or other characteristics are attributable to that area. Examples of PGIs include beers (Münchener Bier, Ceskobudejovické Pivo), meat (Scotch Beef, many types of French poultry) and also bakery products and fish (Scottish Farmed Salmon).

- A Traditional Specialties Guaranteed (TSG): where a product must be traditional (at least 25 years of existence) either in its composition or means of production. Therefore, this quality scheme is not directly linked to a specific location (i.e. Jamon Serrano is produced across all parts of Spain).

The EU Regulation 543/2011 introduces the European marketing standards and stipulates the consumers' right to receive products ensuring minimal quality confirming their expectations along with the ability to compare prices between various features of the same product. All three GIs schemes have logos that can be used for registered product marketing to communicate foodstuffs quality and authenticity to final customers and justify the premium price. Thus, the GI schemes aim to benefit both customers and producers, however, high quality authentic foodstuffs production and optimal use of support for farmers' incomes requires complex encouraging structural measures (Rangnekar, 2004).

In Latvia, the first GI was obtained in 2013 by a Kurzeme region traditional baked product called "sklandraushi". Obtaining the GIs by canned sprats will help to protect Latvian traditional product reputation and maintain expected product quality by eliminating the influence of suboptimal foodstuff producers to the market. For final customers, it will help to indicate the quality product and make an informed choice meeting their expectations regarding taste, odour and other characteristics attributed to the quality canned sprats.

The research aims to evaluate theoretical and economic background of GI-labelling and possibilities for GIs introduction to canned sprat industry in Latvia as well as sketch the relevance of GI introduction to Latvian canned sprats.

To achieve the aim, the following specific research tasks are defined: 1) to analyse the market information asymmetries and relevant issues concerning communication of quality towards end-users; 2) to evaluate economic rationale of GI-labelling; 3) to identify economic foundations for GIs introduction to canned sprat industry in Latvia.

Research methods applied: the monographic, descriptive and analysis methods. The research employed scientific papers on economic development, GI case studies interpretation, protected geographical identification and other trademarking tools' role in producers' and customers' protection.

\section{RESEARCH RESULTS}

\section{Market information asymmetries and communicating the quality}

Being a part of intellectual property protection instruments and a type of a trademark, the GI is closely associated with the information asymmetries between sellers and consumers. The economic theory justifies the protection of GIs as a solution to the problem of asymmetric information in various market sectors (Akerlof, 1970; Moschini et al, 2008). Akerlof (1970) was the first to introduce the notion of a "lemon market" to the economic theory. In his classic example concerting the used car market, there are clear information asymmetries between second-hand cars sellers possessing but not disclosing the essential information about cars characteristics, which does not allow a customer to consider the best option and to make the most rationale choice, whilst increasing their chances to buy a "lemon", i.e. something they would not opt to if having the full information.

The economic rationale for GI schemes cover such factors as consumer loyalty and especially trust and contribute to protection of resources invested in building products reputation from industry opportunists offering products of suboptimal quality. In the food industry the significant information asymmetries concern two aspects: product quality and product "credence-related aspects" (Moser et al., 2011). In fact, the credence aspect can be attributed to the geographical origination of a product, where it is a part of the essential product specification. Credence aspects directly influence the quality of a product, however, not necessarily can be easily ascertained by a customer at any stage of purchase, even after the foodstuff is consumed, i.e. by taste or smell (Moser et al., 2011, Torjusen et al. 2001; Grunert et al. 2004; Moschini et al 2008). Thus, the quality can be conveyed via two channels or a combination of both: a product intrinsic attributes or "extrinsic indicators and cues" demonstrated by a producer, seller or controlling body (Caswell et al. 2002). Moschini et al (2008) point out that GIs is an effective tool to overcome the information asymmetry especially for the high-quality products, which has no means to clearly communicate the quality level prior to purchasing. Therefore, for foodstuff, which quality depends on the location of origins, an external certification eligible only for qualifying products as well as notorious monitoring of the situation is crucial (Caswell and Mojduszka 1996; Becker 1999, Moser et al., 2011).

On the other hand, producers who are dependent on customer credence, which is applicable to foodstuffs in most cases, are looking for information asymmetries reducing due to brand building and reputation investments made during a product lifespan. Business opportunists selling products of a sub-optimal quality on the market jeopardize and ultimately 
impede market functioning as a result of trust breach and driving out honest enterprises from the market, exactly as it was demonstrated by Akerlof (1979) in the market of automobile "lemons". The GI schemes introduction for the high-quality products helps to protect the potential buyers of high quality goods and potential sellers of such goods in the relevant price range present in the market from business opportunists seeking to give their poor quality goods for quality.

Trademarking as tool to overcome information asymmetries. In the situation of asymmetric information, high-quality foodstuffs customers' loyalty and trust can be jeopardized by the "unpredictable nature of quality" (Akerlof, 1970) and presence of sub-optimal products on the market. A number of authors indicate reputation as a main factor to overcome the asymmetric information by signalling a guarantee of a certain level of quality and other aspects that customers can anticipate when buying a certain product (see i.e. Rangnekar, 2004, Grossman and Shapiro, 1988). A traditional mean aiming to overcome information asymmetry on the market and to protect investments in building reputation has been the institution of trademarking and branding displayed to customers via visual identifications such as distinctive signs and communicated in advertising and packaging. In the food industry, such additional instruments as voluntary certification schemes for agricultural products and foodstuffs also provide means to overcome information asymmetries in the market and ensure producers' compliance with specifications, which may include requirements on environmental protection, animal welfare, the odour and taste of a product and fair trade. However, the schemes work only one-way to ensure more comprehensive information for customers, while not providing any means for reputation and market protection against opportunistic approach.

Historically, trademarks and GIs are underpinned by a common rationale aiming to help customers and producers confront the information asymmetries in the market and possess more control over the situation. In both cases, information is conveyed through distinctive signs guarantying that relevant quality expectations are not compromised. However, at the fundamental level there are two fundamental differences between trademarks and GIs:

1. Trademarks are attributed to goods of an enterprise and are not linked to any territory (Borg E. et al., 2013), whereas for GIs, the geography is the most essential and non-transferrable distinctive qualification serving to identify products eligibility for a GI.

2. As an intellectual property sign, trademarks are possessed by a single enterprise, thus, denying all other market players the right to use the trademark (Moschini G. et al., 2008). In contrast, GIs are not limited to a particular producer, but rather imply that there are numerous players in a certain geographical area seeking to collectively obtain a legal protection for their food stuffs.

Since the GI does not belong to a single company but rather to a product and is used by many companies simultaneously, the economic theory defines GIs as a type of collective monopoly right (Borg E. et al., 2013; Benavente, 2010; Takenaka, 2013). According to Benavente (2010), the collective monopoly rights aim to close the entry to the market to producers either within or outside the relevant geographic area. Besides defining a geographical location where a foodstuff can be produced, it also stipulates the production mode and as well as ingredients to eliminate opportunists not able to ensure quality and authenticity, thus, compromising the market and honest producers.

\section{Economic rationale of GI-labelling introduction}

Any mechanisms aimed to sustain and develop the business can be successful only if extra sales (turnover) exceed the expenses required at a scheme or a tool introduction and implementation stage. Upon introduction the GI schemes, businesses are confronted with extra administrative costs required for registration, the application process and following regular checks by controlling public agencies, operational expenses required to adjust the production mode in accordance to the confirmed product specification (if any).

Zisidis (2014) provides the following formula for GIs additional value calculation: unit production cost for GI final products / raw materials included only specific expenses for GI production (cost of inputs + cost of labor + administrative costs for GI production + indirect costs specific to GI production + depreciation of fixed assets specific to GI production (i.e. excluding depreciation of non-specific fixed assets and general expenses). The author demonstrates, the added value has been satisfactory for the producers and reached the average value premium rate in the EU 27 for GI products in comparison to equivalent non-GI products (ibid.). Rangnekar (2004) also indicates that customers are willing to pay premiums for quality that is associated with GI-labelled products. At the same time Aragrande et al. (2013) findings show that premiums are widely differentiated across the foodstuffs variety and can range from $+100 \%$ to marginal $+3 \%$. Nonetheless, the author provides a clear evidence that processed GI products are mostly associated with higher increase of price premiums in comparison to unprocessed (i.e. fresh fruit and vegetables).

GIs - collective reputation resulting in a collective responsibility and need for quality control. Investment in sustaining and improving quality and reputation naturally decrease gross margins available for producers. As Shapiro demonstrated theoretically (1983), these are price premiums that motivate producers to invest in quality and reputation. According to the author, reputation can lead to profit increase only if quality increase in not directly proportional to production price increase (i.e. upgrading production lines or production mode). In addition, as Moschini G. et al. (2008) indicate, high-quality authentic foodstuff production is, in a majority of cases, associated with a fragmented production structure implemented by individual farmers or producers who are typically too small to consistently invest in reputation and effectively convey the information about the high quality of their product directly to a consumer.

Within the collective quality schemes, the reputation is extrapolated to all club members, which allows them to save on reputational investments, however, as a result, this makes the most direct competitors interdependent. The main benefit enjoyed through a club good is a collective reputation, which covers all club members through the traceable GI sign, which can be described as a common property resource available to all the players on the market (Winfree and 
McCluskey, 2005; Benavente, 2010). In the other hand, the collective dimension implies the need to facilitate direct competitors' cooperation and overcome the co-called prisoner's dilemma. At the same time, each member in the club can jeopardize reputations of all individual members at the collective level. As Benavente (2010) mentions this is the main argument why governmental or para-governmental in case of Pan-European quality schemes intervention is needed to develop food standards and schemes and both overcome the information asymmetry in the market and limit market entry opportunity to business opportunists jeopardizing already fragile mostly rural and regional authentic production. She also highlights the need for a strong monitoring and in many cases subsidization from the governmental institutions.

In addition, there is much evidence that the heterogeneity of commodity quality in developing countries is higher than in developed countries. Winfree and McCluckey (2005) highlight that collective reputation is especially crucial when a consumer does not personally know an individual producer (in contrast to a situation, when food stuff is bought from a relative or a locally known producer, i.e. neighbour). This makes the GIs especially relevant to export-oriented food stuff producers: GIs as a recognized feature granted by a state control bodies can be employed to confirm and guarantee the quality of products exported.

The literature suggests the introduction of quasi-public institutions as the main facilitators and coordinators of the GI processes (Benavente, 2010, Barjolle and Sylvander, 2000; Albisu, 2002; Sylvander, 2002). Such institutions as Chambers of Commerce or Industry associations typically link together local producers, who must cooperate with governmental administrative and controlling institutions and the European Commission. Rangnekar (2004) indicates that quasi-public institutions are best positioned to resolve "collective action problems" and help to build trust because they simultaneously represent interests of each producer and of a sector in general. Given the social dimension connected to the GI schemes, the structural support events can be initiated and supported by the regional and national authorities in order to promote GI-labelling introduction to a sector.

\section{Economic foundations for GIs introduction to canned sprat industry in Latvia and recommendation}

For countries only reaching their full economic potential, including post-Soviet Eastern European countries, the GIs is a very promising tradition-and-reputation-driven tool holding an added value features of socio-economic development promotion especially in the rural areas. In Latvia, a huge number food stuffs can qualify to one of the GIs schemes provided by the European Commission. Introducing the schemes to more products in the region will facilitate their appreciation and protection in the global market, which is essential for export-oriented segments.

Overall, according to the DOOR database published by the European Commission, currently there are 1.402 products registered under one of the GI protection schemes and 139 products in the application phase. The majority of the GIs come from Mediterranean countries. From Latvia, there are 5 products registered and one in the approval process: PDO - 1 (Latvian large grey peas), PGI - 2 (Carnikava lamprey and Rucava white butter), TSG - 3 (Jāņu cheese, salted rye bread, sklandrausis). Latvian producers first applied to the scheme in 2013.

Latvian canned sprats is one of the food stuffs that can be eligible to obtain a GI-labelling and would benefit from the certification both in the local market and exported. According to Nelson's classification (1970), canned sprats fall into the experience goods category. Therefore, quality and ensuring customers' expectation are essential for the industry sustainability and ultimately existence. Experience goods are especially sensitive towards the information asymmetry, since a "lemon" can be ascertained only upon consumption. Due to long lasting consumption traditions, currently at the canned sprats market, there is a significant number of products that mismatch the overall production specifications and undermine consumer expectations both when it comes to odour, fish size and density and other characteristics. Since canned sprats term designates a product not a producer, this influences the reputation of all industry players which, in a vast majority of cases, are small enterprises struggling to confront this trend and efficiently signal the quality to restore the reputation.

Besides, the intention to introduce a GI scheme in the sprat production sector in Latvia is not exclusively individual profit driven but also aims to contribute to overall socio-economic development of the rural regions of Latvia. Being an integral sector in rural economy, the fish processing sector plays a significant role in regional sustainability and traditions preservation. Obtaining a European level certification through a GI scheme for Latvian canned sprats, will facilitate intellectual protection and excluding opportunists from the market, both local and international, and will contribute to solving a number of acute problems in the sprat production sector in Latvia.

Overall, the five key structural events need to be mobilized to realize the potential of a GI-labelling introduction to the canned sprats sector in Latvia:

1. Defining the canned sprats' specification and product differentiation according to the GI standards. This includes defining the name of the product, the type of product, the description of the product, the description of the production method, the description of the specificity of the product and the traditional description, as well as the minimum quality requirements so the inspection body (Food and Veterinary Service) can verify the conformity of the product with one of the schemes.

2. Identifying the benefits and drawbacks of the GI schemes implemented at the EU (PDO/PGI/TSG). However, there is no clear indication on profit-wise distinctions between PDO versus PGI products when compared to standard products in the literature (Benevente, 2010), the choice of the scheme is very much dependent on the sector-specific production factors as well as specifications that should be collectively agreed on. Further elaboration is required to evaluate which scheme is the most beneficial for the Latvian canned sprats segment.

3. Understanding of the application process and what are essential factors that will lead to the effort success. Learning from previous cases and issues encountered could be an integral factor resulting in a successful application and including the product to the register. 
4. Running marketing campaigns in collaboration with authorities. The literature suggests (Aragrande et al., 2013; Zisidis, 2014) that the success of policy measures promoting the scheme is directly connected with consumers' awareness of the GI, its labelling, and the measures' economic and social dimensions. For instance, Aragrande et al., 2013, indicate that the degree of recognition of EU GI logos by consumers in different Member States links with the extent of differential margins for GI production. This is especially relevant to communicating the higher quality of GI labelled foodstuffs, the intensity of controls and stimulating consumer demand for quality food.

5. Exploring the potential export volume and the definition of prospective market niches within the framework of the single market. On average $78 \%$ of the GI-labelled foodstuffs are consumed at the local market (Zisidis, 2004). Nonetheless, this factor is hugely segment-specific and as Aragrande et al. (2013) indicate, the GI status was found to have promoted access to new export markets in most cases. The GIs serve as an additional mechanism in promoting increased foreign market penetration. Given that in Latvia more than $90 \%$ of canned sprats are exported, this dimension holds a significant potential for GI-labelled canned sprat. This factor needs further elaboration.

\section{CONCLUSIONS}

The GI-labelling has been proved to be an important tool contributing to producers and customers' protection and complementing traditional trademarking. In Latvia, GI-labelling introduction to canned sprats is seen as beneficial for both producers and customers. For producers, it will provide an additional mechanism to diminish or eliminate the presence of sub-optimal products on the market. For customers, along with reduction of information asymmetries' volume, it will ensure improved and consistent product quality by introducing collective responsibility between producers. The GI-labelling introduction will also promote exporting capabilities especially to Western European countries, which, given the current geopolitical situation, are strategically a priority markets and are also more familiar with the concept of geographical identification. A further detailed elaboration of the indicated key structural events in order to employ the benefits of the scheme as well as a weighted analysis of benefits and losses for the industry and consumers in practice is required.

\section{REFERENCES}

1. Akerlof, G.A., 1970. The market for" lemons": Quality uncertainty and the market mechanism. The Quarterly Journal of Economics, Vol. 84, Iss. 3, pp.488-500. https://doi.org/10.2307/1879431

2. Aragrande M. et al. 2013. Study on assessing the added value of PDO/PGI products by the European Commission. Available at https://ec.europa.eu/agriculture/external-studies/added-value-pdo-pgi_en (Accessed 10/08/2017)

3. Barjolle, D. and Sylvander, B., 2000. Some factors of success for origin labelled products in agri-food supply chains in Europe: market, internal resources and institutions. Actes et communications-Institut national de la recherche agronomique. Economie et sociologie rurales, pp.45-71.

4. Blakeney, M., 2014. The protection of geographical indications: law and practice. Edward Elgar Publishing. https://doi.org/10.4337/9781782546726

5. Borg, E., Gratzer, K., 2013. Collective brand strategy, entrepreneurship, and regional growth: The role of a protected designation of origin (PDO). Journal of World Economic Research, Vol.2, Iss. 3, pp. 26-38. https://doi.org/10.11648/i.jwer.20130203.11

6. Caswell, J.A., Mojduszka, E.M., 1996. Using informational labelling to influence the market for quality in food products. American Journal of Agricultural Economics, Vol. 78, Iss. 5, pp.1248-1253. https://doi.org/10.2307/1243501

7. Gehrig, T., 1993. An information based explanation of the domestic bias in international equity investment. The Scandinavian Journal of Economics, pp.97-109. https://doi.org/10.2307/3440137

8. Grossman, G.M. and Shapiro, C., 1988. Foreign counterfeiting of status goods. The Quarterly Journal of Economics, Vol. 103, Iss. 1, pp. 79-100. https://doi.org/10.2307/1882643

9. Grunert, K.G., Bredahl, L. and Brunsø, K., 2004. Consumer perception of meat quality and implications for product development in the meat sector - a review. Meat science, Vol. 66, Iss. 2, pp. 259-272. https://doi.org/10.1016/S0309-1740(03)00130-X

10. Moschini, G., Menapace, L. and Pick, D., 2008. Geographical indications and the competitive provision of quality in agricultural markets. American Journal of Agricultural Economics, Vol. 90, Iss. 3, pp. 794-812. https://doi.org/10.1111/j.1467$\underline{8276.2008 .01142 . \mathrm{x}}$

11. Moser R., Raffaelli R. and Thilmany-McFadden D., 2011. Consumer Preferences for Fruit and Vegetables with Credence-Based Attributes: A Review. International Food and Agribusiness Management Review, Vol. 14, Iss. 2, pp. 121-142

12. Rangnekar, D., 2004. The socio-economics of geographical indications. Research report UNCTAD-ICTSD Project on IPRs and Sustainable Development, Iss. 8. Centre for the Study of Globalisation and Regionalisation, Warwick University, United Kingdom

13. Takenaka, T. ed., 2013. Intellectual property in common law and civil law. Edward Elgar Publishing. https://doi.org/10.4337/9780857934376

14. Torjusen, H., Lieblein, G., Wandel, M. and Francis, C.A., 2001. Food system orientation and quality perception among consumers and producers of organic food in Hedmark County, Norway. Food quality and preference, Vol. 12, Iss. 3, pp. $207-216$. https://doi.org/10.1016/S0950-3293(00)00047-1

15. Winfree, J., McCluskey, J., 2005. Collective reputation and quality. American Journal of agricultural Economics, Vol. 87, Iss. 1, pp. 206-213. https://doi.org/10.1111/j.0002-9092.2005.00712.x

16. Zisidis O. 2014. Do PDO and PGI foodstuffs have value added to stakeholders? Unpublished dissertation carried out at the Wageningen University, Faculty of Food Safety Law. 